\title{
Local variations in reporting deaths to the coroner in England and Wales:
}

\section{A postcode lottery?}

\author{
Maxwell Mclean ${ }^{1}$, Jason Roach ${ }^{2}$, Rachel Armitage ${ }^{3}$
}

\section{Introduction}

A coroner is an independent judicial officer responsible only to the Crown and must be a barrister, solicitor or medical practitioner of not less than five years standing ${ }^{4}$. Their legal and professional autonomy is unmatched in other judicial settings. There are currently 114 Coroners jurisdictions in England and Wales served by 98 Coroners $^{5}$.

There is no statutory duty placed upon a medical practitioner (e.g. GP) to report a death to the Coroner. The legal duty resides with the Coroner to hold an inquest when defined circumstances apply - for example deaths which are violent or unnatural, or sudden and of unknown cause, or in prison. ${ }^{6}$ Limited advice as to which cases should be reported is to be found within blank medical certificate booklets, in Office of National Statistics (ONS) Advisory Group Publications, in bespoke advice leaflets such as that issued by the Medical Protection Society and tellingly, in locally produced guides issued by some Coroners to medical practitioners working in their areas. In many locally produced guides, coroners go beyond spelling out national provisions and seek to impose additional 'local rules', instructing doctors to report to the coroner all 'deaths within 24 hours of admission to hospital', after 'late diagnosis or treatment', or 'fractures or falls' or 'dementia'.

Start et al (1995),[1] reported the findings of a study in which 196 clinicians and four coroners' staff were invited to complete a postal questionnaire describing 12 fictitious case studies (10 of which contained a clear indication through national guidelines for referral to the coroner). $97 \%$ of participating General Practitioners failed to recognise all those deaths which should have been reported for further investigations. In contrast all participating coroner's staff correctly identified all of the reportable cases in the study. Start and colleagues concluded that some doctors held disturbing misconceptions in relation to the coronial system with implications for the evasion of medico-legal investigation, resulting in consequences including serious crime going undetected to loss of industrial pension or other appropriate compensation for relatives of the deceased (Start et al, 1993). The main confusion was found to lie between accidents and deaths associated with medical treatment

\footnotetext{
${ }^{1}$ Corresponding author, University of Huddersfield, Crime and Policing Group, Queensgate, Huddersfield HD13DH U1078679@hud.ac.uk

${ }^{2}$ Reader in Criminology, University of Huddersfield, Crime and Policing Group

${ }^{3}$ Reader in Criminology, University of Huddersfield, Crime and Policing Group

${ }^{4}$ Section 2(1) Coroners Act 1988

${ }^{5}$ Coroners Statistics 2011 England and Wales Ministry of Justice Statistics Bulletin.

${ }^{6}$ Section 8(1) Coroners Act 1988
} 
as putative causes of death, with further confusion arising as a result of local variations in coroners' practices thereby shaping doctors' subsequent decisions to report. For example, there is persuasive evidence in Tom Luce's (HMSO 2003),[2] fundamental review of coroner services that the present system fails to identify some suicides, drug related deaths and deaths in which adverse reactions to prescribed drugs may have contributed.

Berry and Heaton Armstrong (2005),[3] describe in their review of the coroner system a flawed process which requires comprehensive revision and is poorly understood to the extent of widespread ignorance by those within the medical profession who have to use it. This, they contend, is not helped by an inconsistent and unprofessional approach by coroners who cannot agree on what is a death from natural causes and what is not. Roberts et al (2000),[4] demonstrated considerable variation in the way coroners approach borderline 'natural cause' cases. Sixteen clinical scenarios were circulated to coroners asking for a verdict and explanation, 64 were returned and there was near consensus as to verdict (> $80 \%$ concordance) in only two of the 16 cases. The comments made for each case indicated that the differences reflected varying personal attitudes of each coroner. Thus coroners set their own 'local tone' as to what might be considered a natural death (and therefore potentially not reportable to the coroner) and what might be an unnatural death (and therefore reportable).

The conclusion arrived at by Berry and Heaton Armstrong is that the investigation of death continues to rely upon the application by medical practitioners of standards set variably by local coroners. Whether or not this is satisfactory practice depends upon the value attached to national consistency. Certainly the Crown Prosecution Service and the criminal courts are subject to extensive national guidance in the attempt to limit inconsistent or idiosyncratic decision making, and there seems no reason why this should apply less to the process of death investigation.

The Government is presently reforming the process of death certification by appointing medical examiners (expected implementation by 2014) to provide independent scrutiny of the cause of any death which is not reported to a coroner. The aim is to simplify and strengthen current certification arrangements, improve the quality and accuracy of data on cause of death and prevent multiple deaths going unnoticed and unchallenged (Department of Health 2012),[5]. It is envisaged that in future medical examiners will have the discretion to report a death to the coroner according to an agreed national protocol which sets out the minimum level of scrutiny that must be applied. In an update produced for coroners (Department of Health 2012(a)),[6] deaths reported to a coroner are said to be expected to decrease from the present $46 \%$ national average to around $35 \%$ although this is likely to differ in each area depending on its current baselines and local factors.

\section{Analysis of reporting rates to coroners in England and Wales}

In the 1950 's, fewer than $20 \%$ of registered deaths were reported to the coroner. That figure is now $46 \%$.

\footnotetext{
${ }^{7}$ MOJ 2011, p.1
} 
The tables below were developed by comparing data held by Office of National Statistics (ONS) on registered deaths in local authority areas in England and Wales and data held by the Ministry of Justice (MOJ) on deaths reported to the current 114 coroner's jurisdictions $^{8}$ to show local reporting patterns for the ten years (2001-2010).

Table 1 below shows the ten areas in England and Wales with the highest reporting rates for the period (2001-2010), and Table 2 the lowest. Where coroner jurisdictions (and local authorities) have been amalgamated in the last 10 years the registered and reported deaths figures have been included in the current jurisdiction area. This does mean that the results, on some occasions, whilst reflecting the practices in an area over the decade, may not accurately reflect current practices in so far as they are shaped by the incumbent coroner rather than his or her predecessors in jurisdictions swallowed up during the period ${ }^{9}$. Reporting rates for other jurisdictions are available from the writer on request.

Table 1 - The ten highest reporting rates of registered deaths to coroners (E\&W 20012010)

\begin{tabular}{|l|l|}
\hline Coroners Jurisdiction - Highest 10 & $\begin{array}{l}2001-2010 \text { overall reporting rates of } \\
\text { registered deaths }\end{array}$ \\
\hline Plymouth and South West Devon & $87 \%$ \\
\hline Leicester City and South Leicestershire & $71 \%$ \\
\hline Blackburn, Hyndburn and Ribble Valley & $70 \%$ \\
\hline Inner North London & $70 \%$ \\
\hline
\end{tabular}

${ }^{8}(\mathrm{n}=111)$ With the exception of Queens Household and Isles of Scilly for very low numbers and City of London, for which deaths registered could not be obtained separately (included in Inner North London). Absolute accuracy in registered deaths could not be achieved for 13 coroner's jurisdictions due to MOJ composition being based on parts of parishes. A standard approach was taken whereby data was allocated to the jurisdiction which MOJ composition suggested had much the greater part of a parish. No jurisdiction was composed in this way alone, the vast majority being a combination of unitary authorities or metropolitan boroughs and thereby matching with ONS data.

\footnotetext{
${ }^{9}$ Notes for completion on the MOJ coroner collection form (2010) state that 'Section (i) (deaths reported to the coroner) should include all cases in which coroner investigated the circumstances of a death personally or by his officer, by letter or telephone...'

We are therefore satisfied that all relevant cases should be recorded, making our analysis valid in terms of which deaths are reported. There should be no case, for example, for coroner's officers rejecting reports of death without recording the fact of the report. We contend that the coroner has vicarious responsibility for all investigations under their jurisdiction and that comment on their decision making, by reference to their areas overall output, is valid.
} 


\begin{tabular}{|l|l|}
\hline Manchester City & $70 \%$ \\
\hline Newcastle upon Tyne & $69 \%$ \\
\hline Peterborough & $68 \%$ \\
\hline Torbay and South Devon & $63 \%$ \\
\hline Liverpool & $62 \%$ \\
\hline Stoke on Trent and North Staffordshire & $62 \%$ \\
\hline
\end{tabular}

Table 2 - The ten lowest reporting rates of registered deaths to coroners (E\&W 20012010)

\begin{tabular}{|l|l|}
\hline Coroners Jurisdiction - Lowest 10 & $\begin{array}{l}2001-2010 \text { overall reporting rates of } \\
\text { registered deaths }\end{array}$ \\
\hline Gloucestershire & $32 \%$ \\
\hline South Northumberland & $31 \%$ \\
\hline North Yorkshire Western District & $31 \%$ \\
\hline Neath and Port Talbot & $31 \%$ \\
\hline East Lancashire & $31 \%$ \\
\hline South Shropshire & $22 \%$ \\
\hline Powys & $22 \%$ \\
\hline North and East Cambridgeshire & $22 \%$ \\
\hline Rutland and North Leicestershire & $21 \%$ \\
\hline Stamford & $12 \%$ \\
\hline
\end{tabular}

Reporting rates thus ranged from $12 \%$ of registered deaths in one jurisdiction to $87 \%$ in another with no obvious explanation in features which distinguish high and low reporting areas. An obvious question is whether high rates are consistently so. This was checked by calculating a product moment correlation coefficient comparing reporting rates in the first and last year of the period under study. This proved to be extremely high, suggesting that the relative rates are stable over time. ${ }^{10}$

This was further checked by correlating rates for comparison of data nine years apart and eight years apart and so on, again supporting the conclusion that jurisdictions have stable relative rates of reporting. Reporting rate differences must therefore be attributable to some combination of local demography or local medico-legal practice which is consistent over time.

${ }^{10}$ The relationship was investigated using Pearson product-moment correlation coefficient. There was a very strong positive correlation between the two variables of reporting rates for 2010 and $2001, r=.900, n=111, p<.0005$ 
Figure 1 below represents the total reporting rates to coroner for 2001-2010 for all jurisdictions ${ }^{11}$ (plotted in $5 \%$ bands). The mean reporting rate is calculated at $45 \%$ of all registered deaths in a jurisdiction and the standard deviation is $12 \%$.

\section{Figure 1 - reporting rates of deaths to coroners, all jurisdictions (E\&W 2001-2010)}

\section{(Insert Figure 1 here)}

Eighty-three jurisdictions (75\%) lie within 33\% and 57\% reporting rates (one STDEV above and below the mean), with 11 jurisdictions having reporting rates of less than $33 \%$ and 17 jurisdictions having reporting rates of $57 \%$ and above.

When the findings are placed on the geographical map of jurisdictions, there does appear to be a probable inverse relationship between larger jurisdiction areas and lower reporting rates to the coroner. Possible factors (only speculative here) might be distance from a coroner's office, or necessary self-sufficiency in large rural communities, or indeed the relative lack of supervisory or peer oversight in less densely populated areas.

Highly populated areas reported more deaths (a larger caseload) of course, but there was no relationship found between the reporting rate and size of the population ${ }^{12}$. For example, the two coroner jurisdictions with the highest populations (Essex\&Thurrock and North London) had reporting rates of $36 \%$ to $59 \%$ respectively. There was however some relationship found between higher levels of deprivation and higher reporting rates to the coroner ${ }^{13}$. This is likely to reflect a population less well known to general practitioners through health inequalities and therefore less capable of certification without referral to the coroner. Significant differences could still be found though, for example in Blackburn and Manchester North, areas with similar levels of deprivation, reporting $70 \%$ and $41 \%$ of all deaths respectively.

Thus, there appears to be no obvious demographic reason for such wide variations found in local reporting rates.

The mean post mortem rate for 2010 was found to be $46 \%$, ranging from $20 \%$ to $66 \%$. As expected, more reported deaths brought more post mortems but there was found to be a moderate negative correlation between higher reporting rates and post mortem rates ${ }^{14}$, that is areas in which a greater proportion of registered deaths were reported tended to conduct proportionately less post mortems on those deaths.

\footnotetext{
${ }^{11}$ With the exception of Queens Household and Isles of Scilly for very low numbers and City of London, for which deaths registered could not be obtained separately (included in Inner North London)

${ }^{12}$ Investigated using Pearson product-moment correlation coefficient using the variables reporting rate (for 10 years) and 2010 population figures calculated by summing local authority area populations according to the current jurisdiction composition provided by MOJ, $r=.022, n=111$, ns.

${ }_{13}^{13}$ Using variables reporting rate (for 10 years) and 2010 IMD data for local authorities E\&W only (using the highest ranked deprivation score within each jurisdiction published by Dept for Communities and Local Government 24/03/2011), $r=-.399, n=99, p<.0005$.

${ }^{14}$ Using variables reporting rate (for ten years) and PM rate (2010, in MOJ 2011 Statistics Bulletin pp. 20-23), $r=-.423, n=111, p<.0005$
} 


\section{Inquest Verdicts}

The author has analysed all inquest verdicts across all jurisdictions (England and Wales) from 1995 to 2011 inclusive. Initial analyses ${ }^{15}$ demonstrate that individual jurisdictions are consistent over time in their proportionate use of inquest verdict types. Yet jurisdictions vary widely across the country in verdict use suggesting that verdict patterns may be more a product of an individual coroner's decision making style than a reliable indicator of local patterns of death. Even jurisdictions with similar overall case loads report very different verdict profiles. This 'consistent variance' is a key focus of this research.

The following table offers an example of the range of proportionate verdict use across jurisdictions for 2011 only (MOJ 2011) ${ }^{16}$ and demonstrates wide variation in use of verdicts across England and Wales. Of course there is a link back here to reporting patterns, as for example, a coroner with low use of the natural causes inquest verdict may be one whose guidance to doctors yields fewer cases which suggest a natural death.

Table 3 - Six main verdicts, share of all verdicts by jurisdiction (E\&W 2011)

\begin{tabular}{|l|l|l|l|}
\hline $\begin{array}{l}\text { Coroners Verdict (2011) } \\
\text { (England and Wales) }\end{array}$ & $\begin{array}{l}\text { Average share of all verdicts } \\
\text { (all jurisdictions) }\end{array}$ & $\begin{array}{l}\text { Range } \\
\text { Highest }\end{array}$ & $\begin{array}{l}\text { Range } \\
\text { Lowest }\end{array}$ \\
\hline Suicide & $14 \%$ & $33 \%$ & $2 \%$ \\
\hline Industrial Disease & $9 \%$ & $32 \%$ & $1 \%$ \\
\hline
\end{tabular}

15

The relationship between the 6 most common verdicts (which account for $98 \%$ of all 2011 verdict outcomes) between 2011 and 2009 was investigated as a test analysis using Pearson product-moment correlation coefficient. There was a consistently strong correlation for all years between the variables of 'other verdicts' and 'natural causes', ( $r$ between .946 and .905); and a similarly strong and consistent across years positive correlation for the verdicts of industrial disease, suicide, accidents and open verdicts, $r$ between .894 and .834; $\mathrm{n}=112, \mathrm{p}<.0005$

${ }^{16}$ MOJ Ministry of Justice (2011) Coroners Statistics 2011 England and Wales. London: The Stationery Office, p.16 


\begin{tabular}{|l|l|l|l|}
\hline Accident/misadventure & $29 \%$ & $58 \%$ & $1 \%$ \\
\hline Natural causes & $28 \%$ & $58 \%$ & 0 \\
\hline Open verdict & $8 \%$ & $32 \%$ & 0 \\
\hline Narrative verdict & $12 \%$ & $68 \%$ & 0 \\
& & & \\
\hline
\end{tabular}

\section{The reporting of death according to the sex of the deceased}

When death reporting rates in England and Wales (2001-2010) are looked at according to the sex of the deceased $49 \%$ of male deaths (range $81 \%$ to $13 \%$ ) were reported to the coroner compared to $39 \%$ of female deaths (range $70 \%$ to $11 \%$ ). Jurisdictions with high (or low) reporting rates for men were found to have high (or low) reporting rates for women. $\left[{ }^{17}\right]$ Again jurisdictional reporting rates appeared quite consistent over time with the relationship dropping from very strong to strong for male deaths and to moderate for female deaths when the first and last years of the data set (2001-2010) are correlated. $\left[{ }^{18}\right]$ Deaths of men, therefore, in this study were found on average to be $26 \%$ more likely to be reported to the coroner than deaths of women. This held across all jurisdictions in England and Wales (and in some areas up to $48 \%{ }^{19}$ more likely). Since women die later than men, it would be crucial to examine age-specific reporting rates, for which data are not readily available.

17 Ten year male and female reporting rates were investigated using Pearson productmoment correlation coefficient. There was a very strong positive correlation between the two variables, $r=.975, n=111, p<.0005$

${ }^{18}$ The relationship between male and female reporting rates 2001 and 2010 was investigated using Pearson product-moment correlation coefficient. There was a strong correlation between the two male variables, $r=.739, n=111, p<.0005$ and a moderate correlation between the two female variables, $r=.691, n=111, p=<.0005$

${ }^{19}$ Bridgend and Glamorgan Valleys reporting rates of registered deaths 2001-2010; Male $68 \%$ and Female $46 \%$ 


\section{Further Research - coronial decision making}

One might consider the reporting of a death to the coroner as the first stage in a three stage decision making process which describes our system of death investigation. Once a death has been reported, it is subject to two further fundamental coronial decisions, first whether to proceed to inquest and second what the resulting inquest verdict should be.

There are proportionately fewer inquests for women when compared with men. For men, $16 \%$ of all deaths reported to coroners (2001-2010) proceeded to inquest while for women that figure was $8 \%$. Once at inquest, verdicts of natural causes were recorded more often for women $(28 \%)$ than for men $(22 \%)$. So, fewer women were reported to the coroner, fewer women proceeded to inquest and fewer women at inquest were considered to have died unnaturally. For unnatural deaths, men were over-represented in industrial disease and suicide verdicts while women were over-represented in narrative verdicts and accidents.

There is thus evidence of different verdicts being reached differentially according to the sex of the deceased. Analyses of difference in proportionate use of verdicts by sex of the deceased suggest that some coroners are 'gendered' in their approach to inquest verdicts, that is they are consistently more likely to favour a particular verdict when dealing with a death, according to the sex of the deceased.

The degree to which decisions are gendered in different jurisdictions appears to be consistent over time for all verdicts except industrial disease, where the association between year and degree of 'genderedness' diminishes over time $(r=.82, p<.001)$. The degree to which different verdicts are gendered varies across jurisdiction, with the verdicts 'unlawfully killed' and 'drug non-dependent' being the most highly gendered, ie the proportions of verdicts being particularly different according to gender.

\section{Conclusions}

\section{Take home messages}

- The proportions in which deaths are reported to the coroner in England and Wales varies widely across coronial jurisdictions. Local rates are consistent over time.

- Coroners in England and Wales vary widely in their use of verdicts. Local profiles of verdicts are consistent over time.

- Deaths of women in England and Wales are less likely to be reported to the coroner than men. Female deaths reported are less likely to proceed to inquest than male deaths. Female deaths proceeding to inquest are less likely to result in a verdict of unnatural death than male deaths. 
- Some coroners seem especially 'gendered' in their decision making, in that they are consistently more likely to favour a particular verdict according to the sex of the deceased.

\section{Figure Legend}

Figure 1 - reporting rates of deaths to coroners, all jurisdictions (E\&W 2001-2010)

\section{Contributors}

Maxwell Mclean designed data collection tools, collected data for the whole analysis, wrote the statistical analysis plan, cleaned and analysed the data, and drafted and revised the paper. He is guarantor. Jason Roach monitored the data collection, analysed the data and revised the draft paper. Rachel Armitage monitored the data collection, revised the draft paper.

\section{Funding}

This research received no specific funding

\section{Competing Interests}

None to declare.

\section{Licence for Publication}

The Corresponding Author has the right to grant on behalf of all authors and does grant on behalf of all authors, an exclusive licence (or non exclusive for government employees) on a worldwide basis to the BMJ Publishing Group Ltd and its Licensees to permit this article (if accepted) to be published in JCP editions and any other BMJPGL products to exploit all subsidiary rights, as set out in our licence (http://group.bmj.com/products/journals/instructions-for-authors/licenceforms/). 


\section{References}

1 Start, R.D, Usherwood, T.P, Dorries CP, Carter N, Cotton DWK, 'General practitioners' knowledge of when to refer deaths to a coroner', British Journal of General Practice 1995, 45, pp. 191-193

$2 \mathrm{HMSO}$, Death certification and investigation in England, Wales and Northern Ireland. The report of a fundamental review (2003), CM 5831, London: The Stationery Office

3 Berry C. and Heaton-Armstrong A', 'A review of the coroner system in England and Wales: a commentary' Clinical Medicine 2005; 5 (5): pp.455-459

4 Roberts, I.S.D, Gorodkin L, and Benbow E, 'What is a natural cause of death? A survey of how coroners in England and Wales approach borderline cases Journal of Clinical Pathology 2000, 53: pp.367-373

5 Department of Health 'Death Certification reforms' letter dated 11 April 2012 from Rt Hon Andrew Lansley CBE MP to Local Authorities 2012. (Online) Available at

https://www.gov.uk/government/uploads/system/uploads/attachment data/file/146719/dh 13 3693.pdf.pdf (accessed 30th April 2013)

6 Department of Health (a) 'Death Certification Reforms in England and Wales Update for Coroners' 2012. (Online) Available at

https://www.gov.uk/government/uploads/system/uploads/attachment data/file/126979/Death -Certification-Reforms-Update-for-Coroners-Oct-12.pdf.pdf (accessed 30th April 2013) 